\title{
LA VIDEOPOLÍTICA EN CAMPAÑA: EVOLUCIÓN DEL SPOT ELECTORAL EN ESPAÑA ENTRE 2004 Y 2011
}

Carmen Julia Carceller Cobos ${ }^{1}$ : Universidad Católica San Antonio de Murcia. España. cjcarceller@alu.ucam.edu

\section{RESUMEN}

La videopolítica es una de las principales herramientas de marketing con las que cuentan los partidos políticos. Campaña tras campaña, los responsables de comunicación de los partidos pugnan por presentar los spots más novedosos, pegadizos y, a la vez, nocivos para los partidos en la oposición. Las campañas políticas marcan la agenda del día en los medios y, a menudo, la presentación de spots políticos es noticia en los informativos televisivos. Como veremos, YouTube se ha convertido en el principal canal de difusión de estos anuncios políticos, que han encontrado en esta herramienta el lugar perfecto para crecer y expandirse, llegando prácticamente a la totalidad de los ciudadanos. Este trabajo, además de acercarnos a la historia de la videopolítica, nos ayudará a conocer las tendencias y la evolución del spot electoral entre 2004 y 2011 en los dos principales partidos españoles. El estudio se justifica por el crecimiento que ha experimentado la videopolítica gracias al auge de YouTube, por la cada vez mayor presencia de estas piezas de marketing político en los informativos televisivos, y porque realizar un estudio basado en aspectos tan variados como la tipología, la temática, los objetivos y la utilización de recursos visuales y sonoros puede aportarnos una imagen global de las tendencias actuales de la videopolítica en España. El caso práctico de este trabajo se fundamenta en el análisis cualitativo y comparativo de un total de 41 spots elaborados por el PP y el PSOE para las campañas electorales de 2004, 2008 y 2011.

PALABRAS CLAVE: Videopolítica - Campaña electoral - Spot - Anuncio político - Youtube - PP - PSOE

\footnotetext{
${ }^{1}$ Autor correspondiente:

Carmen Julia Carceller Cobos: Becaria de investigación del Grupo Comunicación Política e Imagen de la Facultad de Ciencias Sociales y de la Comunicación de la Universidad Católica San Antonio de Murcia. España.

Correo: cjcarceller@alu.ucam.edu
} 


\title{
VIDEOPOLITICS IN CAMPAIGN: EVOLUTION OF ELECTORAL SPOT IN SPAIN BETWEEN 2004 AND 2011
}

\begin{abstract}
Videopolitics is one of the main marketing tools that have political parties. Campaign after campaign, communication officers of the parties vying for present the most innovative spots, catchy and, at the same time, harmful to opposition parties. Political campaigns mark the day's agenda in the media and, often, the presentation of political spots is news on the TV news. As we shall see, YouTube has become the main channel for publishing politicians, who have found the perfect tool to grow and expand, virtually all citizens. This work, in addition to approach us to the videopolitics history will help us understand the trends and developments in the electoral spot between 2004 and 2011 in the two main Spanish parties. The study is justified by the growth who videopolitics has experienced thanks to boom YouTube, by the increasing presence of these pieces of political marketing in the TV news, and because one study based on issues as varied as the type, the theme, the objectives and the use of visual and sound can give us an overall picture of the current trends of videopolitics in Spain. The case study of this work is based on qualitative and comparative analysis of a total of 41 spots produced by the PP and the PSOE to the election campaigns of 2004, 2008 and 2011.
\end{abstract}

KEY WORDS: Videpolitics - Electioneering - Spot - Political Advertisement Youtube - PP - PSOE

\section{INTRODUCCIÓN}

Este apartado pretende ser un acercamiento al fenómeno de la videopolítica a partir de las afirmaciones que diversos autores, como Fischer (2005), Berrocal (2004), Carabajal (2011) o Sartori (2003) han hecho sobre ella, también desde una visión negativa. Será, además, un recorrido por su historia, analizando desde el origen y las causas de su nacimiento hasta los nuevos canales de difusión utilizados en la actualidad; esto ayudará al lector a comprender las tendencias y la evolución del spot electoral en España entre 2004 y 2011. Tras esta breve revisión, se repasarán los datos más significativos de las campañas electorales españolas entre los años 1996 y 2011, y se aportarán diferentes tipologías descritas sobre spots electorales y en las cuales está basado este estudio.

\subsection{La videopolítica como forma expresiva}

Hoy, en plena era de la comunicación, el político que no aparezca en televisión es como si no existiera. Por eso, para los políticos es fundamental "ser parte de lo que la gente quiere ver en pantalla, casi como un "spot", entramados en una política light, manejada a través de los medios de comunicación, creando imágenes" (Fischer, 2005, p.133). La presencia mediática del candidato es clave en comunicación política, pero 
¿por qué? Según Berrocal (2004, p.56), "el electorado observa en los mass media las informaciones y propuestas de sus dirigentes", lo que, a su vez, ayuda a forjar una decisión sobre quién debe gobernar. Así pues, lo que interesa al candidato es tener visibilidad para conseguir el voto del ciudadano, mostrándole una imagen positiva y diferenciada.

La videopolítica conjuga dos aspectos populares y masivos de la vida del hombre: por un lado, la televisión (vídeo, del latín videre, que significa "ver"); por otro, la política. Son muchos los autores que han tratado de darle un significado a esta herramienta. Para Carabajal (2011, p.2), "la videopolítica es un fenómeno que alude a la superficie sobre la cual se ve reflejada la política". Fischer (2005, p.133), en cambio, se centra más en el lado publicitario del vídeo político:

La videopolítica es la manera de hacer política mediatizada, principalmente, por la imagen televisiva, en donde las empresas de publicidad dirigen las agendas de muchos temas ciudadanos y de gobierno, creando imágenes atrayentes que venden a los electores como publicidad.

Para Sartori (2003), la videopolítica se refiere solo a uno de los múltiples aspectos del poder del vídeo, que incide en los procesos políticos y nos enseña cómo "ser políticos" y cómo "gestionar la política".

Los medios de comunicación y de información se han convertido en piezas vitales para los actores políticos, pero ese poder mediático aumenta el distanciamiento entre el pueblo y sus élites. Los electores tienden a guiarse más por las imágenes que por las ideas, que a menudo se evaporan, convirtiéndose en promesas incumplidas. Los individuos se transforman en meros espectadores de una serie que podríamos llamar Juego Político y esperan con impaciencia la emisión de su capítulo diario, elegido, evidentemente, por sus actores. Los medios de comunicación son solo los canales elegidos para tal fin.

La videopolítica, como mantiene Gutiérrez-Rubí (2010a, p.1) “es una gran oportunidad para que, desde el sentido del humor (y del ridículo), la crítica ácida y mordaz o los argumentos más razonados, se generen piezas frescas, ágiles y oportunas que permitan empaquetar creativamente las propuestas de los partidos y candidatos".

La propaganda política o electoral ha tenido como objetivo siempre influir en las opiniones, emociones, actitudes y decisiones de los electores a través de la persuasión. En este punto, es conveniente diferenciar persuasión de manipulación. La persuasión hace al espectador libre de creer o no el mensaje; la manipulación supone "robar a las personas su libertad de elección" (Martín Salgado, 2002, p.25). En muchos casos, esta persuasión corre a cargo del candidato o líder político y de su capacidad para desenvolverse delante de una cámara. Por este motivo, si hay una figura clave dentro de la videopolítica esa es la del líder. En política, se pueden distinguir diferentes tipos de líder. Según Berrocal (2004, p.54) “el líder ideológico, que define objetivos y busca reformas, el líder transaccional, que gestiona y que es especialmente eficaz en 
momentos de estabilidad, o el líder carismático, que suele surgir en tiempos de crisis y que se fundamenta en lo emocional".

$\mathrm{Si}$ se tuviese que elegir un modelo de líder pensando en el actual sistema comunicativo, este sería el líder "transformador": "aquel que tiene visión, ideas propias, sabe inspirar a los demás y persuadir al electorado" y que "apela tanto al intelecto como a las emociones de su auditorio, con temas sencillos y memorables como 'cambio', pero también con ideas de fondo que explican a qué responden esos temas" (Martín Salgado, 2002, p.92-93). A estos cuatro líderes, Martínez Rodrigo (2005, p.213) añadiría un cuarto, el "manipulador ideológico", que "intenta modelar el espíritu de las personas y pueblos con el fin de adquirir el dominio sobre ellos de forma rápida, contundente y masiva". El manipulador ideológico juega con la ventaja de que "al carecer de cohesión interna, la masa es fácilmente dominable y manipulable por quienes buscan el poder." (Martínez Rodrigo, 2005, p.213). ${ }^{2}$

Cualquier información que los votantes reúnen sobre un candidato influye en la formación de la "imagen" de este como líder y puede contribuir a su decisión final, pero cada votante reacciona de distinta manera ante la misma información (Berrocal, 2004). Podría decirse, entonces, que el objetivo de la videopolítica es presentar al candidato aproximándose al modelo del líder perfecto, a través de tres herramientas principalmente: acciones, discurso y cualidades. Por acciones entendemos "cambios en la forma de vestir, de hablar, de peinarse o retoques estéticos más o menos oficiosos", ya que es importante que "los políticos aprendan a adaptarse a todas las exigencias de la producción y el guion" (Berrocal, 2004, p.58). ${ }^{3}$

Ya hemos hablado anteriormente de la importancia de los mass media como transmisores de informaciones sobre los candidatos o partidos. El problema para los expertos en marketing político es que estos no se pueden controlar. Berrocal (2004, p.6364) sostiene que "la imagen proyectada por el líder en cada una de sus apariciones televisivas depende, en ocasiones, del control político en las empresas informativas". La solución para los medios de comunicación será dirigir el discurso que emite el poder, en cuanto al contenido, y la imagen que van a recibir del líder político que se emite en este discurso (Ramonet, 1994).

Berrocal (2004, p.60) defiende que "los anuncios televisivos que presentan a los candidatos en distintas situaciones están claramente diseñados para conseguir o

\footnotetext{
2 En 1960, los debates electorales entre Richard Nixon y John Kennedy (EE.UU) marcaron un antes y un después en el estudio de la influencia de la imagen televisiva. Nixon, en su libro Seis Crisis, reconoció que su derrota electoral tuvo mucho que ver con no saber estar en el nuevo medio: "Dediqué demasiado esfuerzo a la sustancia del mensaje, y demasiado poco al aspecto. Me fijé mucho en lo que tenía que decir y poco en cómo" (citado en De Cora, 1991, p.37).

${ }^{3}$ En 1980, Reagan venció a Carter (EE.UU). Aunque las respuestas del segundo eran más contundentes, Reagan tenía más aspecto de presidente. En 1984, Reagan volvió a vencer, esta vez a Walter Mondale, que tras su derrota comentó: "Creo que en la política moderna se necesita de un dominio de la televisión mayor del que yo podía alcanzar [...] Creo que ya no va a ser posible presentarse para la presidencia si no se es capaz de crear confianza y comunicación todas las noches. Así es como se habrá de hacer" (citado en Perry, 1986, p.192). Es decir, la política se convierte en un show donde importa más el cómo decir que el qué decir (Carabajal, 2011).
} 
mantener cierta percepción sobre el líder." Para esta autora (Berrocal, 2004), las cualidades o atributos que más interesa destacar en un líder son "competencia", "experiencia", "paciencia", "precaución", “capacidad de decisión" y "valentía" y, junto a ellas, aspectos personales como "resistencia", "honestidad", "justicia", "mente abierta", "seguridad", "energía" y "atractivo físico".

\subsubsection{Visión negativa de la videopolítica}

No todos los autores consideran adecuada la videopolítica como herramienta de marketing político. Para Fischer (2005, p.130), "supone la centralidad perversa de la televisión y la publicidad en los contenidos democráticos, o mejor dicho, en la carencia de ellos". A veces confundimos el hecho de vivir en una sociedad democrática con ser realmente libres, porque en estas sociedades "se promete, ante todo, la cota más alta de libertad, aunque sea a costa de la eficacia". (Martínez Rodrigo, 2005, p.213).

Cuando el espacio político se convierte en espacio televisivo, cambian las reglas del juego y aparece el espectáculo. Como comenta Carabajal (2011, p.4), "es la TV la que impone las reglas y normas de conducta, o de etiqueta". A partir de ese momento, todo es posible. Podemos encontrarnos ante un sistema débil de partidos, escondido tras una industria comunicacional fuerte, regida por tres reglas: espectáculo, formato televisivo y simulacro (Fischer, 2005). En este sentido, prosigue la autora (2005, p.130), "la transmisión de imágenes a distancia uniforma los gustos e intereses, genera amnesia política, convirtiendo sus problemas en espectáculo, crea una participación imaginaria, que transforma en seres manipulados y pasivos a los ciudadanos". Así, los individuos carecen de voz, son marginados, olvidados, excluidos... y solo se les pide una cosa: que voten. Como sostiene Carabajal (2011, p.5), el pueblo "parece estar relegado al mero procedimiento electoral de depositar una papeleta en las urnas".

Uno de los principales peligros de la videopolítica es que puede devenir en manipulación, concepto que en páginas anteriores hemos diferenciado de persuasión. La manipulación es un obstáculo para alcanzar una sociedad más justa de individuos de pensamiento libre y riguroso (Martínez Rodrigo, 2005).

Antes de pasar a hablar de la finalidad y de las formas o posibilidades de manipulación, digamos que esta se basa en la seducción. Según Martínez Rodrigo (2005, p.212), "el manipulador no habla a la inteligencia, no respeta la verdad ajena; actúa astutamente sobre los centros de decisión de su público con el fin de arrastrarle a tomar decisiones que favorecen sus propósitos".

Las personas, como seres comunicativos, necesitamos el lenguaje, la palabra, tanto como respirar. Con todo, el lenguaje puede llegar a resultar peligroso si se hace de él un uso fraudulento, ya que, debido a su efectividad y a su ambigüedad, puede ser "tierno o cruel", "amable o displicente", un instrumento puesto a disposición tanto "de la verdad como de la mentira" (Martínez Rodrigo, 2005).

\subsection{Historia: causas y origen del nacimiento de la videopolítica}


Comprender las nuevas tendencias en comunicación política exige remontarnos a sus orígenes, es decir, al nacimiento de la civilización. Entonces, las habilidades de los sabios se basaban, fundamentalmente, en la retórica y en la elocuencia. Pensemos, por ejemplo, en grandes maestros como Aristóteles y Maquiavelo, que hicieron buen uso de la persuasión en sus discursos.

Los adelantos científicos y tecnológicos, que en un principio nacen para dar respuesta a las demandas y necesidades del ser humano, son la muestra más evidente de la evolución de la sociedad y producen a la vez cambios en el funcionamiento de su vida. Disciplinas como la informática y las telecomunicaciones han tenido grandes repercusiones en la política, más concretamente en todo lo que se refiere a la comunicación. Pero estos avances que, a priori, repercuten positivamente en la vide de los ciudadanos, no siempre benefician a todos por igual. ${ }^{4}$

En la primera mitad del siglo XX, aparecen nuevos medios de comunicación: el cine, la radio, la televisión y cada vez cobra más importancia el concepto de comunicación política. En este sentido, Martín-Jiménez (2012, p.896) recuerda el importante papel que jugó la pequeña pantalla como instrumento de transmisión de la Transición democrática en España a través de "los mensajes de Suárez y los miembros del parlamento, las campañas televisivas o los contenidos de programación habitual [...] con el fin de propiciar una opinión pública que respaldara las decisiones de los dirigentes del proceso".

A lo largo de los años, los diferentes formatos propagandísticos de las formaciones políticas han ido evolucionando. Gran "culpa" de ello la tiene Internet, canal del que se hablará más adelante. Con todo, los vídeos son la herramienta audiovisual más apreciada por los partidos políticos por su efectividad. Peña (2011, p.24) explica por qué:

La retórica política que hoy conocemos se dirige a un público educado en el audiovisual y, por ello, acostumbrado al consumo masivo de mensajes de este tipo. La comunicación electoral, destinada fundamentalmente a conseguir apoyos entre el electorado potencial, encuentra así en el spot una herramienta adecuada para persuadir a través de la televisión.

Las causas del nacimiento de la videopolítica se deben encontrar, según Fischer (2005, p.133), en "la pérdida de institucionalización y el desgaste de los partidos". El spot electoral nace en EE.UU en la campaña presidencial de 1952, que enfrentó al General Eisenhower y a Adlai Stevenson. En el caso español, el spot electoral se estrena en 1977, tras el cambio de régimen político, en la etapa de la transición política que desembocó en la promulgación de la Constitución y acabó con la celebración de las primeras elecciones democráticas. Los factores económicos, socioculturales, políticos e históricos afectan al desarrollo de la comunicación política y cuanto más democrático sea un régimen político, más amplia y continua será esta (Carabajal, 2011).

${ }^{4}$ El nivel económico y cultural de cada individuo puede influir en el acceso de este a los medios telemáticos. 
Tanto en el caso norteamericano como en el español, los primeros spots políticos estaban basados en la imagen del líder hablando a cámara ${ }^{5}$, exponiendo sus propuestas y desgranando su programa electoral (Peña, 2011). Ahora, en cambio, se suele prescindir bastante de la imagen del candidato; los spots actuales tienden más a buscar la emoción a través de imágenes que la transmisión de ideas o de propuestas que raras veces se cumplen y que en la mayoría de los casos terminan por olvidarse tras la llegada de nuevos anuncios.

\subsubsection{Nuevos canales}

El marketing político ha experimentado grandes cambios desde sus orígenes, en los años ochenta. A partir de los noventa, el modo de hacer política adquiere nuevas formas. Los formatos se han modificado para adaptarse a los nuevos tiempos, a medios masivos (como la televisión e Internet), y a las demandas de los votantes. La finalidad, en términos publicitarios, es lograr que el público adquiera el producto anunciado para, de esta forma, aumentar las ventas y asegurarse el éxito comercial.

Antes de abordar en el tema de los canales de difusión de los vídeos electorales, deben conocer las limitaciones con las que cuentan los partidos políticos.

Con la publicación de la Ley Orgánica 2/2011, de 28 de enero, que modificó la Ley Orgánica 5/1985, de 19 de junio, del Régimen Electoral General (LOREG), se produjeron una serie de restricciones enfocadas a la reducción del peso de la publicidad y propaganda de los partidos políticos, en favor de la exposición y debate de sus programas y propuestas, y a la minoración de los gastos electorales.

Según el artículo 60, apartado 1, de la Ley Orgánica 2/2011 del Régimen Electoral General, sobre publicidad electoral en medios de comunicación, "no pueden contratarse espacios de publicidad electoral en los medios de comunicación de titularidad pública ni en las emisoras de televisión privada". El artículo 55, apartado 3, de la misma ley sostiene que: "el gasto de las candidaturas en este tipo de publicidad no podrá exceder del 20 por ciento del límite de gastos previsto en los artículos 175.2, 193.2 y 227.2, según el proceso electoral de que se trate".

Con este panorama, no es de extrañar que los partidos políticos busquen otras vías o canales de difusión gratuitos donde colgar sus vídeos de campaña. Así, en los últimos años, el desarrollo del vídeo electoral online ha ido paralelo a la "explosión" que ha experimentado YouTube, como medio de comunicación, en otras áreas de interés para los usuarios de Internet (Crespo, Garrido, Carletla, Riorda, 2011). Según GutiérrezRubí (2010a, p.1), "la Generación YouTube [...] está cambiando la manera de comprender el dato, el conocimiento. Y, en consecuencia, la política". En este sentido, es indiscutible el papel cumplido por YouTube, como web 2.0, para el crecimiento del

\footnotetext{
${ }^{5}$ Busto parlante o talking head ads, tipo de spot del que hablaremos más adelante.
} 
spot presidencial online. Podría decirse, incluso, que esta web se ha consolidado como plataforma audiovisual líder en spots electorales.

Pero, ¿por qué YouTube y no otra plataforma? Los motivos son bien sencillos. Es fácil de usar, es gratuito, posibilita a los usuarios navegar cómodamente ordenando los contenidos según los criterios de más vistos, más comentados, favoritos... También permite al candidato o a su partido crear canales propios donde subir y difundir sus vídeos de campaña entre una audiencia más amplia, a modo de propia web (Crespo et al., 2011), y a sus simpatizantes colgar vídeos caseros, generalmente humorísticos, conocidos como vídeos virales. ${ }^{6}$

¿Cómo se difunden estos spots y vídeos virales a través de YouTube? El equipo de comunicación política sube a YouTube los vídeos creados para la campaña como livestreaming vídeos o imágenes en directo de los actos y eventos programados. Así, estos clásicos spots de elaboración propia adquieren una mayor difusión y repercusión como vídeos virales, siendo reproducidos en blogs o redes sociales. Además, como sostienen los autores (Crespo et al., 2011, p.234), los eventos son transmitidos en tiempo real.

No solo permiten un mayor seguimiento público de los actos programados, sino que permiten que acontecimientos propagandísticos que no son cubiertos por los medios de comunicación convencionales tengan una repercusión, una vez que han sido anunciados en la página web del candidato o en sus sitios en comunidades virtuales como Twitter o Facebook.

En el caso de líderes carismáticos, el hecho de subir discursos a la web los hace más accesibles a simpatizantes y electores, y les ofrece la posibilidad de reutilizar este material para crear algo original, divertido y creativo, como el conocido "Yes We Can" de Barack Obama (Crespo et al., 2011). De esta manera, también los simpatizantes pueden crear canales no oficiales, aportando nuevas ideas independientes de la línea de campaña, lo que según Crespo et al. (2011, p.236), "garantiza un mayor tráfico viral de los vídeos de propaganda electoral que en el caso de aquellos productos audiovisuales generados exclusivamente desde el equipo oficial de nuevos medios". En definitiva, como sostienen algunos investigadores (Crespo et al., 2011, p.238), "las nuevas formas de activismo electoral están comenzando a sustituir por su alcance masivo a los tradicionales spots de campaña, que tienen un alto coste tanto de producción, como de emisión".

\subsection{La videopolítica en España}

En España, los vídeos electorales han ido evolucionando en busca de nuevos formatos. Sin llegar a desaparecer, el busto parlante o talking head ads, muy habitual en las

\footnotetext{
${ }^{6}$ Gálvez Clavijo (2010, p.138) define el marketing viral en los siguientes términos "el marketing viral puede definirse como aquellas técnicas del marketing que utilizan la interconexión de los usuarios en las herramientas 2.0 para aumentar la difusión de las campañas lanzadas por las marcas. Tal como su propio nombre indica, se trata de que cierto tipo de mensajes se divulguen a través de un flujo de información incontrolado, como si de un virus informático se tratase."
} 
primeras elecciones democráticas, ha dado paso a otros modelos que tratan de empatizar con los electores.

A continuación, se hará repaso general por las campañas electorales españolas entre el año 1996 y el 2011. En el apartado "Discusión de resultados" ampliaremos la información sobre las campañas electorales de 2004, 2008 y 2011 basándonos en los datos revelados por nuestro estudio.

Un punto de inflexión, reconocido por distintos investigadores, fue la emisión de un spot negativo en 1996 bautizado como el "Vídeo del Dóberman". El vídeo fue elaborado por el partido que ostentaba la presidencia del Gobierno en ese momento, el PSOE, cuando las encuestas anunciaban una clara derrota frente a su adversario, el Partido Popular. En el spot, que tiene una duración de dos minutos y medio, el PSOE apela al miedo a través de la tensión. En él se establece una comparación entre la "España en positivo" (la España del PSOE), y la "España en negativo" (la España del Partido Popular), con grandes diferencias basadas en la música (tétrica en el caso del $\mathrm{PP}$, alegre en el caso del PSOE), el color de la imagen (en blanco y negro cuando hace referencia al PP, en color cuando se refiere al PSOE), y la voz en off (de ultratumba cuando habla del PP, optimista cuando lo hace del PSOE). Parece que el spot no tuvo los efectos esperados y el PSOE perdió las elecciones y la presidencia del Gobierno. Tal vez tuvo un "efecto búmeran" pero, como veremos, los spots negativos han estado presentes siempre desde ese momento en sucesivas convocatorias.

Para las elecciones del año 2000, los principales partidos, PP y PSOE, repitieron los mismos formatos de spots que en 1996. El PP presentó un vídeo amable, cargado de logros y propuestas, hablando de "hechos", bajo el lema "Vamos a más", y con una estética parecida a la del videoclip, del que hablaremos más adelante. Por su parte, el PSOE presentó un spot negativo que incluía al presidente, José María Aznar, con semblante serio, distante, antipático, y al candidato del PSOE, Joaquín Almunia, en imágenes cargadas de luz y de color (Peña, 2011). En esta campaña, el eslogan del PSOE fue "Lo próximo" y en su spot se afirmaba: "Mintiendo se han hecho populares".

La campaña de 2004, por su parte, estuvo marcada por los atentados del 11-M, cometidos tres días antes de los comicios, convocados para el 14 de marzo. Uno de los spots presentados por el PSOE en esta ocasión estaba centrado en temas como la catástrofe del Prestige o la Guerra de Irak. Una vez más, el PSOE centraba su campaña en una estrategia de desgaste del adversario a través del spot negativo. El PP repitió de nuevo esquemas y presentó un anuncio alegre, lleno de luz, de color y de mensajes positivos. Ambos spots finalizaban con una imagen del candidato hablando a cámara. En el caso del PSOE, Rodríguez Zapatero lanza una serie de preguntas basadas en la crítica al adversario, mientras que en el caso del PP, Mariano Rajoy emite un mensaje optimista, ofreciendo un equipo de hombres y mujeres preparados y haciendo un llamamiento a la unidad (Peña, 2011). La utilización de estas técnicas se relaciona con el cambio de enfoque en los spots centrados en componentes emotivos y de poco contenido político. 
Para las elecciones de 2008, el PP adopta el spot negativo empleado en otras convocatorias por el PSOE con un formato de parodia acerca de la crisis económica y financiera que el presidente Zapatero negaba. Otro de los spots del PP simulaba una baraja de naipes con la cara de Rodríguez Zapatero formando una construcción, que finalmente se desploma, y un mensaje: "porque hay cosas que caen por su propio peso". El PSOE continuó eligiendo los spots negativos, pero, esta vez de una forma menos agresiva que en ocasiones anteriores, planteando dicotomías: "los unos frente a los otros", "nosotros y ellos" (Peña, 2011).

En la convocatoria de 2011, el PSOE se centró más en mostrar una imagen de su candidato, Alfredo Pérez Rubalcaba, con ideas de progreso y justicia social bajo el lema "Pelea por lo que quieres". El PP, que se sabía claro vencedor según todas las encuestas, hizo uso del mensaje "Súmate al cambio", con mensajes de esperanza y la promesa de resolver el mayor problema que vivía España: la falta de empleo.

\subsection{Tipos de spots electorales}

Además del pionero spot electoral negativo (del que se ha hablado ya anteriormente y sobre el que se profundizará más adelante), es posible encontrar diversos tipos y clasificaciones de spots electorales.

Previamente, se debe diferenciar el spot electoral del videoclip. Para Fischer (2005, p.134), "la principal diferencia entre el spot y el videoclip radica en los ritmos, mientras en el primero lo dan las pulsaciones de las múltiples imágenes que se sobreponen, en el segundo lo entrega la música, que es su base". Un buen ejemplo de vídeo musical es el "Obama Girl" en el que la joven modelo Amber Lee Ettinger interpreta la canción "I got a Crush... on Obama" mostrando su apoyo al candidato demócrata (Crespo et al., 2011, p.236).

Este estudio se centrará en la clásica división que hizo Devlin (1987) sobre todos los anuncios televisivos de las elecciones presidenciales estadounidenses entre 1952 y 1984, por ser más operativa para los objetivos de nuestra investigación:

- "Busto parlante o talking head ads", que son aquellos en los que solo se ve una cabeza o busto parlante.

- "Anuncios negativos", basados en la descalificación del oponente.

- "Cinéma verite", que muestran una porción de la vida real del candidato: con otros políticos, con sus seguidores, con su familia...

- "Anuncios documentales", que tratan de crear una determinada imagen presentando los logros del candidato a través de un conjunto de eventos, lugares y personas.

- "Anuncios del hombre de la calle", en los que ciudadanos o actores hablan positivamente del candidato o negativamente del oponente.

- "Anuncios de una porción de vida", en los que aparecen actores sosteniendo una conversación "natural" en alguna escena de la vida cotidiana.

- "Anuncios testimoniales", que son aquellos en los que personalidades públicas prominentes hablan sobre el candidato o su oponente. 
- "Bio spot o profile ad", son anuncios biográficos que repasan la trayectoria y los logros del candidato.

- "Anuncios independientes", patrocinados por organizaciones diferentes de las del candidato.

A partir de la tipología de anuncios propuesta por los investigadores de la Annenberg School de la Universidad de Pensilvania, EE.UU (García Beadoux, D’Adamo, Slavinsky, 2005), se hará una clasificación de los spots electorales españoles producidos entre 2004 y 2011 en:

- "Anuncios positivos"7 (de identificación, de carácter mítico o de temas), centrados en las cualidades del candidato.

- "Anuncios de contraste" (directo o implícito), que comparan las cualidades de los candidatos, su trayectoria o sus propuestas con las de su oponente.

- "Anuncios negativos" (avisos de noción, avisos de testigo personal o avisos de periodista neutral), centrados en las debilidades del adversario.

Se tendrán en cuenta, asimismo, otras categorías de anuncios menos frecuentes: anuncios reactivos (confesión, admisión justificada, negación, contraataque, ofuscación o contraimagen), de Johnson-Cartee y Copeland o anuncios de exaltación, de ataque o de defensa, de Trent y Friedenberg (citadas en García Beadoux et al., 2005).

Otros aspectos en los que fijaremos nuestro estudio serán las propuestas, los mitos (en el caso de que los haya), los roles presidenciales, el público al que va dirigido, los objetivos y los temas a los que hacen referencia. Con todo, es conveniente también ofrecer otras clasificaciones que no han sido tenidas en cuenta en nuestro estudio de campo por ser menos específicas. Los vídeos electorales pueden tener diferentes usos según la función que quieran cumplir. Según Gutiérrez-Rubí (2010b, p.1), podemos clasificarlos fundamentalmente en:

1. Vídeos del "día a día", que muestran lo que el candidato y el partido hacen habitualmente: actos, entrevistas en televisión, actividades del partido y de la militancia, videoblog... El objetivo es saber qué hace y qué opina el candidato y qué actividades son interesantes.

2. Vídeos de "interacción", en los que la ciudadanía habla directamente con el candidato o el partido. Pueden hacerse a través de entrevistas o de comentarios en los vídeos o en redes sociales, escogiendo las mejores preguntas, dando los nombres de quienes las hacen, y respondiéndolas siempre. De este tipo de spot, símbolo de cercanía con la ciudadanía, encontramos un precedente en la campaña para las primarias de 2008 en EE.UU. En ella, se hizo una selección de 39 preguntas entre más de 2000 vídeos recibidos. Según Gutiérrez-Rubí (2007, p.1) ofreció "una autenticidad y frescura que lo hizo muy atractivo. Los vídeos transmitían mucha más información que el contenido concreto a responder".

3. Vídeos "del partido y su programa", que tienen como objetivo principal que se hable del partido, de cómo es, de cómo piensa y de lo que dice su gente, de lo

\footnotetext{
7 Para una mayor profundización en la terminología de spots electorales nombrados en este epígrafe pueden consultar en el manual García Beaudoux, et al. (2005), Comunicación Política y campañas electorales. Estrategias en elecciones presidenciales. Barcelona: Gedisa, pp. 41-51.
} 
que representa o puede representar para la sociedad, y de sus propuestas. No deben ser excesivamente largos, sino más bien concisos y adecuados a cada público.

4. Vídeos “en campaña” que tienen como fin, según Gutiérrez Rubí (2010b, p.1), "mostrar qué se hace en campaña, con ideas divertidas, innovadoras y que puedan generar viralidad, que sea sencillo reenviar los vídeos a todos los simpatizantes, pero que estos también los puedan enviar o recomendar a sus contactos".

5. Vídeos de "campañas negativas", del que hablaremos a continuación.

\subsubsection{El spot electoral negativo}

Existe un tipo de spot que permanece más tiempo que los demás en la memoria del espectador debido al impacto que causa: el spot electoral negativo, que suele ser tan polémico como recordado. Como dice Peña (2011, p.23), "la publicidad negativa se recuerda más que la positiva, y el recuerdo constituye una de sus principales bazas, a lo que ha de sumarse la repercusión mediática y el correspondiente efecto rebote que unos medios producen sobre otros en relación con una determinada noticia".

Las campañas políticas que se alimentan de spots electorales negativos son cada vez más frecuentes. El equipo de campaña debe estar preparado para responder a campañas negativas de la oposición. Los spots negativos son vídeos en los que se ataca al oponente, con un alto componente crítico (satírico y divertido). Lo más frecuente es que se produzca una respuesta en forma de ataque de la oposición (Gutiérrez-Rubí, 2010b). Para Peña (2011, p.1), los spots electorales negativos "son aquellas producciones audiovisuales construidas sin más causa que la reprobación del contrincante".

El uso de los spots negativos es frecuente en todas las campañas electorales españolas desde 1996, cuando el PSOE emitió el famoso "Vídeo del Dóberman", del que ya hemos hablado en páginas anteriores. Con todo, quien emplee este recurso debe contemplar siempre, como indica Peña (2011, p.9), "la posibilidad de un efecto búmeran que, lejos de conseguir su objetivo de aniquilar al adversario mediante descalificaciones diversas -con mayor o menor apego a la verdad-, despierte entre los espectadores un sentimiento de compasión hacia la formación agredida".

\section{METODOLOGÍA}

\subsection{Introducción al trabajo de campo}

Entre las múltiples formas de marketing político, se ha elegido la videopolítica como objeto de estudio por ser la herramienta más popular y extendida actualmente en España. Analizar la totalidad de los spots electorales de la historia de la democracia española sería un trabajo titánico, por lo que ha decidido centrar este estudio en los spots electorales presentados por los dos principales partidos, PP y PSOE, para las tres últimas campañas electorales: 2004, 2008 y 2011.

\subsection{Explicación de la metodología}


El análisis cualitativo y el análisis comparativo son las dos herramientas utilizadas en el marco práctico de este trabajo. Se comenzó analizando uno por uno cada uno de los spots seleccionados y, una vez obtenidos los resultados, se compararon los de uno y otro partido hasta llegar a las conclusiones.

Este estudio está basado en el análisis de un total de 41 spots electorales difundidos por el PP y el PSOE en las campañas electorales 2004, 2008 y 2011. Al no existir ningún portal o archivo que recopile todos estos documentos audiovisuales por año y partido político, la elaboración de la lista de spots para analizar fue elaborada por el propio autor, a través de búsquedas independientes en YouTube o en los canales propios que cada partido posee en esta web. El cuadro siguiente es un resumen del número de spots electorales encontrados y analizados:

Cuadro 1. Número de spots analizados por partido y campaña.

\begin{tabular}{|c|c|c|c|}
\hline & $\begin{array}{c}\text { Campaña } \\
\text { electoral } \\
\mathbf{2 0 0 4}\end{array}$ & $\begin{array}{c}\text { Campaña } \\
\text { electoral } \\
\mathbf{2 0 0 8}\end{array}$ & $\begin{array}{c}\text { Campaña } \\
\text { electoral }\end{array}$ \\
\hline PSOE & 1 spot & 7 spots & 10 spots \\
\hline PP & 4 spots & 9 spots & 10 spots \\
\hline
\end{tabular}

Fuente: Elaboración propia.

La diferencia entre el número de spots analizados de uno y otro partido se debe, exclusivamente, a su disponibilidad y visibilidad en YouTube. Esta diferencia no influye de ninguna manera en los resultados del estudio, ya que las estadísticas fueron extraídas de forma independiente. Para el análisis cualitativo, se ha utilizado SPSS (Statistical Product and Service Solutions) como herramienta de tratamiento de datos y análisis estadístico. En primer lugar, se diseñó una tabla basada en los siguientes 20 campos y sus correspondientes clasificaciones:

Cuadro 2. Relación de campos analizados en nuestro estudio.

\begin{tabular}{|c|c|c|c|c|c|c|}
\hline C.1 & C.2 & C.3 & C.4 & C.5 & C.6 & C.7 \\
del spot & $\begin{array}{c}\text { Año de } \\
\text { campaña }\end{array}$ & Autoría & $\begin{array}{c}\text { Recursos y } \\
\text { efectos } \\
\text { visuales }\end{array}$ & $\begin{array}{c}\text { Recursos y } \\
\text { efectos } \\
\text { sonoros }\end{array}$ & $\begin{array}{c}\text { Observaciones } \\
\text { sobre recursos } \\
\text { y efectos }\end{array}$ \\
\hline C.8 & C.9 & C.10 & C.11 & C.12 & C.13 & C.14 \\
Duración & Tipo & Tono & Actividad & Disposición & Propuesta & Mitos \\
\hline
\end{tabular}

\footnotetext{
${ }^{8}$ El campo "Actividad" no se tuvo en cuenta finalmente, ya que implicaba conocer el orden de emisión de todos los spots y su contexto concreto para poder completarlo correctamente.
} 


\begin{tabular}{|c|c|c|c|c|c|c|}
\hline $\begin{array}{c}\text { C.15 } \\
\text { Roles } \\
\text { presidenciales }\end{array}$ & $\begin{array}{c}\text { C.16 } \\
\text { Público } \\
\text { objetivo }\end{array}$ & $\begin{array}{c}\text { Observaciones } \\
\text { sobre el target }\end{array}$ & Objetivos & $\begin{array}{c}\text { Tema } \\
\text { principal }\end{array}$ & $\begin{array}{c}\text { Tema } \\
\text { secundario }\end{array}$ & \\
\hline
\end{tabular}

Fuente: Elaboración propia.

\subsection{Explicación y contexto del objeto de estudio}

PP y PSOE son los dos partidos más activos en lo que a marketing político se refiere: los que mayor número de spots electorales presentan, los que más dinero invierten en sus campañas y los mejores ejemplos de comunicación política a nivel nacional.

Son varios los motivos para elegir la campaña de 2004 como punto de partida del objeto de este estudio. En primer lugar, por la presencia de YouTube como canal de difusión de los spots electorales en la última década. En segundo lugar, porque las elecciones generales de 2004 en España, también conocidas como las del 14-M, estuvieron marcadas por los atentados islamistas del 11-M, ocurridos solo tres días antes. Aunque estos acontecimientos tuvieron lugar fuera del periodo de campaña electoral, estarán muy presentes en la siguiente cita electoral de 2008. Otro motivo de interés para tomar las elecciones generales de 2004 como punto de arranque de este estudio es que en ellas se produjo un cambio de Gobierno. Tras dos legislaturas del PP, las elecciones de 2004 supusieron la victoria del PSOE.

\section{ANÁLISIS Y DISCUSIÓN}

A continuación, se hará un repaso por los resultados más significativos ${ }^{9}$ obtenidos en el trabajo de campo.

En la primera campaña analizada, el PSOE utiliza recursos muy básicos, pero este dato no debe ser tenido en cuenta puesto que, en esta ocasión, solo se contaba con un spot de este partido. El PP, en cambio, emplea más variedad de recursos y más sofisticados. En las dos siguientes campañas, ambos partidos innovan en el empleo de recursos visuales y sonoros, pero tanto PP como PSOE coinciden en la escasa utilización del himno del partido en todas sus campañas.

En cuanto a la duración de los anuncios políticos, desde 2008 se observa una tendencia a presentar spots de una duración cada vez menor. El partido pionero en la utilización de una mayoría de anuncios breves, comprendidos entre 31" y 1', fue el PP. En 2011, el PSOE se decanta por el empleo de estos tiempos, mientras que el PP continúa reduciendo la duración de algunos de sus anuncios políticos a menos de 30".

Analizando los tipos de anuncios electorales presentados por el PP y el PSOE se observa que, si bien en el año 2004 ambos partidos coinciden en presentar un 100\% de

\footnotetext{
9 Para acceder a la totalidad de tablas de datos y porcentajes fruto del presente estudio, así como a la lista spots analizados con sus correspondientes enlaces, contactar con el autor.
} 
"anuncios del hombre de la calle", en las dos siguientes campañas se distancian en la elección de los tipos. El PSOE continúa decantándose por "anuncios del hombre de la calle" en la mayoría de los presentados en 2008 y 2011, mientras que el PP elige, principalmente, "anuncios negativos".

Sobre el tono, lo más destacado es la utilización que hace el PSOE en 2008 del tipo "anuncios positivos de temas", que ya había empleado el PP en el $100 \%$ de los presentados en 2004 y que volverá a emplear de forma mayoritaria en la campaña de 2011.

En cuanto a la disposición, llama la atención la evolución que lleva a cabo el PP. Si bien en la campaña 2004 este partido se emplea en exaltar las virtudes del candidato en todos sus anuncios, en el año 2008 opta por atacar a su oponente en el $90 \%$ de ellos, y en 2011 por repartirlos al 50\% entre la exaltación y el ataque. El PSOE, en cambio, es más lineal a la hora de mostrar su disposición y en las dos últimas campañas ha optado por exaltar las virtudes de su candidato.

En base a las apelaciones (o propuestas) contenidas en los spots analizados, se puede afirmar que en la primera campaña estudiada (2004) ambos partidos coinciden en el tipo y tratan de emocionar positivamente al espectador-elector. En el año 2008, el PP deja a un lado las emociones y apela a la razón proponiendo, básicamente, temas. En la campaña siguiente (2011), se reparte, principalmente, entre las "apelaciones a temas" y las "apelaciones emocionales negativas". El PSOE, por su parte, vuelve a repetir esquemas también en sus propuestas, y en los años 2008 y 2011 presenta, prácticamente en la misma medida, "apelaciones de imagen y/o de carácter" y "apelaciones emocionales positivas".

En el caso de los mitos, el PP no varía en la inclusión de los mismos y opta en las tres campañas analizadas por la utilización de "mitos de mantenimiento", como el del "votante racional". En 2008 y 2011, además, recurre al mito de "nosotros-ellos" para canalizar emociones negativas. Su oponente, el PSOE, elige en la mayoría de los casos mitos de "nosotros-ellos" para las campañas de 2004 y 2008, pero en el año 2011 son sustituidos por "mitos de mantenimiento".

En este trabajo se analizaron también los roles atribuidos a los candidatos en los spots electorales. En el caso del PP, encontramos el rol presidencial del "jefe visionario" en el año 2004 pero, en las dos sucesivas campañas, aparentemente, no se emplean en el uso de un rol presidencial claro. Por su parte, el PSOE, a lo largo de las tres campañas, utiliza los roles del "jefe visionario", del "guardián de valores" y del "gran comunicador", pero como ocurre en el caso del PP, en muchos casos no se aprecia rol presidencial alguno.

En cuanto al público objetivo al que van dirigidos los spots, se observan grandes diferencias entre los presentados por el PP y los del PSOE. Por regla general, el PP dirige la mayoría de sus anuncios a los ciudadanos españoles en conjunto. Esta regla varía un poco en la última campaña, en la que se dirige también a grupos sociales como pensionistas, parados y jóvenes. En cambio, el PSOE se dirige siempre tanto a 
grupos sociales como a grupos partidarios (la izquierda en general y sus votantes más fieles), sobre todo en la última campaña.

Sobre los objetivos, lo más significativo que se puede apuntar es que el PP se emplea, principalmente, en la realización de ataques (sobre todo en el año 2008), y también en el establecimiento de issues. Los objetivos del PSOE, son diferentes, ya que opta por el establecimiento de una imagen, el refuerzo del candidato y en que se identifique su nombre.

En cuanto a los temas de los spots, los más repetidos en el caso del PP son el empleo/desempleo y la economía, mientras que en el caso del PSOE lo son el nivel de vida, la gobernabilidad y la educación.

\section{CONCLUSIONES}

1. Tras un análisis introductorio cuantitativo, se puede afirmar que YouTube, sitio web nacido en 2005, se ha consolidado como canal líder de videopolítica en las dos últimas campañas electorales españolas (2008 y 2011). El número de spots electorales presentados por las dos principales formaciones políticas, PSOE y PP, ha crecido considerablemente desde el año 2004. Además de las características señaladas en el marco conceptual del presente trabajo (gratuidad, fácil manejo y acceso libre a cualquier usuario), la principal causa de este fenómeno se puede encontrar en la libertad de la que goza este canal, situado al margen de las restricciones implantadas por la LOREG ${ }^{10}$. Otro motivo podría ser la compatibilidad que ofrece el formato del spot para ser emitido en televisión y en Internet o en cualquier otro dispositivo que disponga de pantalla y/o conexión 3G.

2. Conforme a los datos obtenidos en el presente estudio, se observa una tendencia a la reducción del tiempo de los anuncios electorales. Las razones que llevan a los partidos políticos a presentar cada vez más spots que no alcanzan el minuto de duración pueden ir, desde la intención de disminuir costes en producción, hasta el convencimiento de una mayor efectividad de los mismos. Con un modelo de anuncio electoral corto es, probablemente, más fácil mantener la atención de un ciudadano descontento con el panorama político que se vive en su país, pero la efectividad de este puede estar relacionada con las preferencias de cada individuo. Una investigación futura, pues, podría relacionar las actuales predilecciones en videopolítica de los ciudadanos con el grado de persuasión de los anuncios políticos.

3. Los resultados de este estudio indican que el tipo de spot político preferido por el PSOE en las tres últimas campañas electorales ha sido el "anuncio del hombre de la calle". En cambio, el PP, que en el año 2004 coincidía con su opositor proponiendo una totalidad de "anuncios del hombre de la calle", ha evolucionado en las dos últimas campañas a un modelo de "anuncio negativo". Este partido, que en 1996 sufrió el

${ }^{10}$ Ley Orgánica 2/2011, de 28 de enero, que modificó la Ley Orgánica 5/1985, de 19 de junio, del Régimen Electoral General. 
ataque de un anuncio negativo11, lanzado por el PSOE, del que salió ileso, se ha vuelto en los últimos años más feroz y agresivo en las formas. Existen, por tanto, diferencias importantes en la elección de la tipología que hace uno y otro partido. Mientras que el PSOE trata de que el espectador se sienta identificado con la forma de pensar o los problemas de los individuos, actores o no, que aparecen en sus anuncios, el PP se esfuerza en descalificar a su principal oponente sembrando el miedo y haciendo que se identifique al candidato, al partido e, incluso, a sus colores, con lo negativo.

4. Los resultados obtenidos sobre los objetivos perseguidos con los spots de cada partido, están relacionados con la tipología de anuncio que elige cada uno. Según los datos obtenidos en las tres campañas, el PSOE opta por utilizar sus anuncios como refuerzo o identificación del nombre de su candidato, mientras que el PP se emplea en la realización de ataques y también en el establecimiento de issues. Lo mismo sucede con los resultados alcanzados en cuanto a la disposición. A lo largo de las tres campañas estudiadas, la principal disposición del PSOE es la exaltación de las virtudes del candidato, mientras que la del PP es el ataque al oponente.

5. En general, se puede afirmar la influencia que el contexto o la situación económica, política $^{12}$ y social ejercen sobre los spots electorales en cada campaña, todo ello sin renunciar a la ironía o al sentido del humor ${ }^{13}$. Ese influjo del contexto se hace muy presente en la elección de los temas de los spots. Así, los principales temas a los que recurre el PP son el empleo/desempleo y la economía, mientras que los elegidos por el PSOE, conocedor de las encuestas que anunciaban una clara victoria del PP en las últimas elecciones, decide eludir esos temas para hablar de gobernabilidad y de educación. Existen también fundamentos para hablar de vigilancia e interacción entre partidos. Así, en ocasiones, podemos encontrar spots de un partido que son respuesta a uno presentado anteriormente por su opositor. ${ }^{14}$

6. Tras la visualización de la totalidad de los spots y el análisis de los recursos visuales y sonoros, se observa, por regla general, una cierta tendencia a la desideologización política en los mismos. La escasa (o ninguna) utilización del himno del partido, de los colores corporativos propios y del logotipo en los anuncios de campaña parecen tender a la neutralidad y huir de un encasillamiento ideológico. La intención podría ser ofrecerse como partidos para todos los gustos, ideas y colores.

\footnotetext{
${ }^{11} \mathrm{El}$ "Vídeo del Dóberman", al que se hace referencia en páginas anteriores.

12 Por ejemplo, en la campaña 2011 el objetivo del 50\% de los anuncios presentados por el PSOE es la identificación del nombre del nuevo candidato a la presidencia, Alfredo Pérez Rubalcaba. Otro ejemplo en la campaña 2011 lo encontramos en el público objetivo al que el PSOE dirige sus anuncios. Llama la atención el llamamiento que hace el PSOE en esta última campaña pidiendo el voto de los suyos (grupos partidarios).

13 En un anuncio de 2008, el PP hace una parodia de la crisis negada por el presidente José Luis Rodríguez Zapatero.

14 En la campaña 2008, el PP responde al spot del PSOE “Con Z de Zapatero” con otro titulado “Con Z de incapaz".
} 
7. Por último, parece pertinente elaborar un perfil de cada partido basado en las tendencias que han sido advertidas tras la realización de este estudio. A los aspectos señalados anteriormente podemos añadir que tras la campaña de 2004 el PP rompe muchos de sus esquemas. Si bien ese año apelaba por entero a emociones positivas, en las dos sucesivas campañas las cambiará por temas y por emociones negativas. Estos datos nos dan muestra de un partido que tiende más a la razón que a la emoción, como si a aquel lema de la campaña electoral de 2008 ("Con cabeza y corazón") le sobrase la segunda parte. Ese antes y después de la campaña 2004 se aprecia también en cuanto al público objetivo al que dirige los mensajes de sus anuncios. En 2004, era únicamente España como grupo geográfico (los ciudadanos españoles en conjunto) pero, en 2008, comienza a dirigirse también a grupos sociales (como las familias) y, en 2011, además, reclama la atención de votantes ajenos. Como anunciábamos en el punto 3 del presente apartado, esa evolución del PP desde la primera campaña analizada (2004) es notable también en la tipología de anuncio predilecto que deja de ser el "anuncio del hombre de la calle" para convertirse en el "anuncio negativo". En resumen, estamos ante un partido con una tendencia basada puramente en lo racional, capaz de cambiar radicalmente sus tendencias si las circunstancias lo requieren, agresivo en las formas y que reclama la atención de todos los ciudadanos en general (aunque en la última campaña haya buscado también el voto de otros grupos sociales y partidarios).

El PSOE, en cambio, es más clásico y varía poco sus esquemas durante el periodo analizado. Desde la primera campaña estudiada se puede observar cómo en sus anuncios deja a un lado los planteamientos racionales buscando, sobre todo, emociones positivas Estos planteamientos emocionales positivos llevan, por supuesto, implícito un mensaje que invita a rechazar las ideas de su oponente. Al contario que el PP, que es más generalista a la hora de pedir el voto, el PSOE prefiere focalizar siempre su llamamiento en los diferentes grupos sociales y en los grupos partidarios, dirigiéndose a los suyos y a la izquierda en general, sobre todo en la última campaña en la que se emplea a fondo solicitando el apoyo de votantes propios. Otro ejemplo claro que demuestra la escasa evolución del PSOE en sus tendencias en videopolítica es su predilección por el "anuncio del hombre de la calle" que ha venido empleando de forma mayoritaria desde la campaña de 2004 .

Finalmente, cabe añadir que este estudio puede tener su continuación en otra investigación futura, una vez que se hayan celebrado las elecciones del año 2015. Sin duda, será interesante comprobar si el PSOE, tras la derrota de las últimas elecciones, cambia su estrategia en videopolítica o si, por el contrario, mantiene la misma línea que en las tres campañas analizadas por este estudio. De la misma manera, se podrá constatar si el PP, una vez recuperado el poder en 2011, evoluciona a un modelo de spot basado más en las emociones que en la razón o repite los esquemas seguidos en las dos últimas campañas.

\section{REFERENCIAS}

Berrocal, S. (2004). Una aproximación a la nueva retórica del líder político televisivo: acciones, cualidades y discurso. Doxa Comunicación. 2, 53-67. 
Carabajal, J.D. (2011). Los nuevos aires en la comunicación política: la TV y la política, una alianza a favor del protagonismo personal. Inferencia Política, 2 (1-8) http:/ / inferenciapolitica.unlar.edu.ar/NUMERODOS/CARABAJAL.pdf.

Crespo, I., Garrido, A., Carletta, I. \& Riorda, M. (2011). Manual de comunicación política y estrategias de campaña. Candidatos, medios y electores en una nueva era. Buenos Aires (Argentina): Biblos/Metodologías

De Cora, J. (1991). Manual del perfecto político. Madrid: Espasa Calpe, Crónicas de Hoy.

Devlin, P. (1987). Political persuasión in Presidencial campaigns, Nueva Jersey: Transaction.

España. Ley Orgánica 2/2011, de 28 de enero, por la que se modifica la Ley Orgánica 5/1985, de 19 de junio, del Régimen Electoral General. Boletín Oficial del Estado, 29 de enero de 2011, núm. 25, pp. 9510-9511.

Fischer, D. (2005). Videopolítica: retórica del vacío. Información Pública. 3(2), 129-142.

Gálvez Clavijo, I. (2010). Introducción al Marketing en Internet: Marketing 2.0 (1 $1^{\mathrm{a}}$ ed.). Málaga: Innova.

García Beaudoux, V., D’adamo O. \& Slavinsky, G (2005). Comunicación Política y campañas electorales. Estrategias en elecciones presidenciales. Barcelona: Gedisa.

Gutiérrez-Rubí, A. (2007). Tengo un vídeo para usted. Diario Siglo21, 321, p.9. Disponible en http://www.gutierrez-rubi.es/2007/08/02/tengo-un-video-parausted/

Gutiérrez-Rubí, A. (2010a). Videopolítica. Diario Público (Edició Catalunya), Artículo 8, Focus Electoral, p.5. Disponible en http://www.gutierrezrubi.es/2010/11/19/videopolitica/.

Gutiérrez-Rubí, A. (2010b). 5 usos de la videopolítica en campaña. Disponible en http:/ / www.gutierrez-rubi.es/2010/08/11/5-usos-de-la-videopolitica-en-campana/.

Martín-Jiménez, V. (2012). Una aproximación a un nuevo campo de estudio sobre la Transición democrática. Los inicios de la comunicación política televisiva en España. Revista de Comunicación Vivat Academia. No Especial, 888-900. http://www.ucm.es/info/vivataca/numeros/n117E/PDFs/VMartin.pdf

Martín Salgado, L. (2002). Marketing politico. Arte y ciencia de la persuasión en la democracia, Barcelona: Paidós.

Martínez Rodrigo, S. (2005). Lenguaje audiovisual y manipulación. Comunicar: Revista Científica Iberoamericana de Comunicación y Educación, 25, 211-220 
Peña, P. (2011). El spot electoral negativo. Revista Latina de Comunicación Social, 66, 399425. http://www.revistalatinacs.org/11/art/939_URJC/18_Palma.html.

Ramonet, I. (1994). "Del canal único y monopólico al caleidoscopio televisivo", en Huertas, F. (comp.): Televisión y política, Madrid: Universidad Complutense.

Sartori, G. (2003). Homo videns. La sociedad teledirigida, Madrid: Taurus.

Trent, J. \& Friedenberg, R. (2000). Political Campaign Communication. Principles and Practices . Westport: Praeger Series in Political Communication.

\section{Carmen Julia Carceller Cobos}

Graduada en Periodismo. Becaria de investigación del Ministerio de Educación en el Grupo de Investigación Comunicación, Política e Imagen de la Facultad de Ciencias Sociales y de la Comunicación de la Universidad Católica San Antonio de Murcia con el proyecto financiado por la Fundación Séneca: “Análisis de los puntos de contacto más eficaces para la creación de la marca política en el público joven". Sus líneas de interés se centran en comunicación política, nuevas tecnologías y medios participativos. 